\title{
Simulation of Elliptical Relay for Long Transmission Line Protection using MATLAB Software
}

\author{
Abhishek Bagh ${ }^{1}$, T. G. Arora ${ }^{2}$ \\ ${ }^{1,2}$ Shri Ramdeobaba College of Engineering and Management, Department of Electrical Engineering, \\ Ramdeo Tekdi, Gittikhadan, Katol Road, Nagpur, India
}

\begin{abstract}
Relays are a key device for protection of transmission lines. It isolates the faulty section of electrical power system from rest of the power system so that the rest portion can function satisfactorily without any severe damage due to fault current. Power swings occur frequently in long transmission lines. Hence for protection of long transmission line, a relay must be chosen so that it is least affected by power swing. Also relay must operate fast to prevent damage and maintain the stability of the system. In classical relay systems, the trip signal is generated after at least one AC cycle. Elliptical relay is least affected by power swings. The algorithm used for the generation of trip signal in proposed method operates the relay within one AC cycle which is much faster than a classical relay system. The simulation results are obtained for both classical relay and the relay system using this algorithm in MATLAB software. This paper presents the modelling of elliptical relay using the classical algorithm and the proposed algorithm in MATLAB software. The conic characteristics are simulated and results are verified in MATLAB software.
\end{abstract}

Keywords: Conic characteristics, microcontroller, power swing, sampling, transmission line angle

\section{Introduction}

An elliptical relay is a non-conventional directional relay. It is a subset of conic section relay. The $\mathrm{R}-\mathrm{X}$ characteristics of elliptical relay is shown in Figure 1. generated after one AC cycle.

The main focus of this paper is modelling of elliptical relay in classical method and in proposed topology using MATLAB software. Simulation is carried out at different system conditions and $\mathrm{R}-\mathrm{X}$ characteristics are plotted using MATLAB software.

\section{Explanation}

Consider the R-X diagram shown in Figure 2.

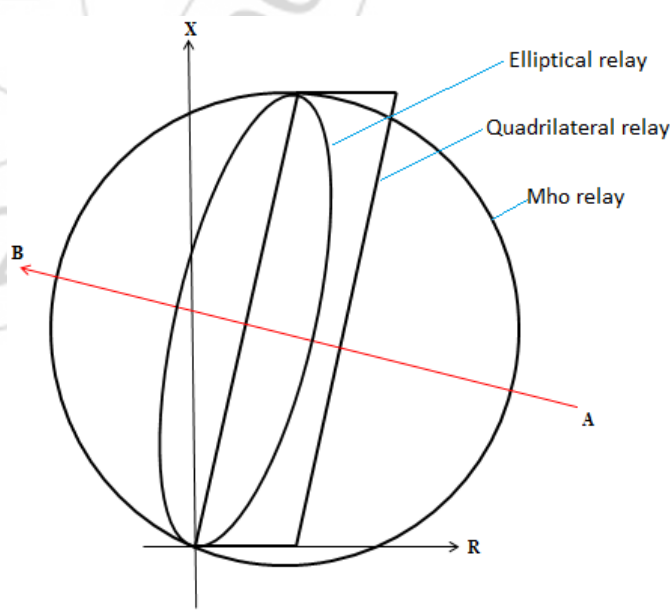

Figure 2: Comparison between mho, quadrilateral and elliptical relay

To minimize the problems of power swings in conventional relays, elliptical relays can be used as a substitute over other relays. Elliptical relays are less affected by power swing as compared to quadrilateral relays.

In conventional algorithms for the calculation of $\mathrm{R}$ and $\mathrm{X}$, its values get calculated after at least one $\mathrm{AC}$ cycle. The root mean square value (RMS) of voltage and current are calculated after one cycle. As a result, the relay trip signal is 


\section{International Journal of Science and Research (IJSR) \\ ISSN (Online): 2319-7064 \\ Index Copernicus Value (2013): 6.14 | Impact Factor (2015): 6.391}

resistance is negligible in long transmission lines as compared to short and medium transmission lines. Thus elliptical relay is suitable for protection of long transmission lines where power swings occur frequently.

\section{Algorithm for calculation of $R$ and $L$}

Transmission line is modelled as simple $\mathrm{R}-\mathrm{X}$ circuit lumped together. In discrete form, we can represent this as

$$
\begin{gathered}
v_{n}=R i_{n}+L \frac{d i_{n}}{d t} \\
v_{n+1}=R i_{n+1}+L \frac{d i_{n+1}}{d t}
\end{gathered}
$$

Also,

$$
\begin{aligned}
& \frac{d i_{n}}{d t}=\frac{i_{n+1}-i_{n-1}}{2 \Delta t} \\
& \frac{d i_{n+1}}{d t}=\frac{i_{n+2}-i_{n}}{2 \Delta t}
\end{aligned}
$$

Where, $\Delta t$ is time interval of sampling.

The $\mathrm{R}$ and $\mathrm{L}$ can be found out by

Where,

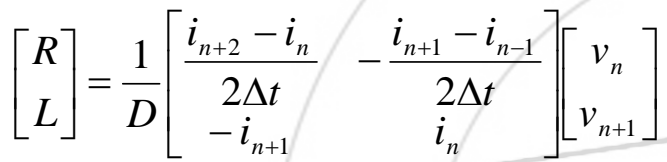

$$
D=\frac{i_{n+2}-i_{n}}{2 \Delta t} i_{n}-\frac{i_{n+1}-i_{n-1}}{2 \Delta t} i_{n+1}
$$

Thus by creating a window of four samples, we can calculate the values of $\mathrm{R}$ and $\mathrm{L}$. Thus the reactance of the relay is given as

$$
X=2 \pi f L
$$

Thus the values of resistance and reactance are calculated.

\section{Embedding elliptical relay characteristics}

In $\mathrm{X}$-Y frame, the equation of ellipse is given by

$$
\frac{x^{2}}{a^{2}}+\frac{y^{2}}{b^{2}}=1
$$

Shifting the ellipse along positive $\mathrm{Y}$-axis we get

$$
\frac{x^{2}}{a^{2}}+\frac{(y-k)^{2}}{b^{2}}=1
$$

Where $k$ is offset along positive Y-axis. Now, rotating the axes in anticlockwise direction we get

$$
\begin{aligned}
& \left(a^{2} \sin ^{2} \theta+b^{2} \cos ^{2} \theta\right) x^{2}+\left(a^{2} \cos ^{2} \theta+b^{2} \sin ^{2} \theta\right) y^{2} \\
& +\left(\left(a^{2}-b^{2}\right) \sin 2 \theta\right) x y-\left(2 k a^{2} \sin \theta\right) x-\left(2 k a^{2} \cos \theta\right) y \\
& +\left(k^{2} a^{2}-a^{2} b^{2}\right)=0
\end{aligned}
$$

Where $a$ and $b$ are major and minor axes respectively.

$\theta$ is the angle shift between new and previous $\mathrm{Y}$-axes.

\section{Classical relay system topology}

In classical relay system topology, the RMS values of voltages and currents are calculated. The power factor of the system is calculated. The resistance and reactance is the calculated by

$$
\begin{aligned}
& R=\frac{V}{I} \cos \phi \\
& X=\frac{V}{I} \sin \phi
\end{aligned}
$$

Where, $\phi$ is the phase shift between voltage and current. Based on the values of resistance and reactance, the distance relay operates.

\section{Simulation of elliptical relay in classical method using MATLAB software}

To study the performance of elliptical relay in classical method, simulation was performed in MATLAB software.

The parameters for line data are

Line impedance $\mathrm{Z}_{\mathrm{L}}=1.08 \Omega$

Transmission line angle $\beta=74.74$ degrees

$\mathrm{a}=0.2$

$\mathrm{b}=\mathrm{k}=0.54$

$\theta=90-\beta=15.26$ degrees

The simulation of elliptical relay in classical method is shown in Figure 3 .The blocks are discussed below

\subsection{Calculation of RMS values of voltage and current}

The RMS value of voltage and current is calculated by the RMS block. The frequency is set at $50 \mathrm{~Hz}$.

\subsection{Calculation of power factor}

For the calculation of power factor, active and reactive power is calculated. Thus, 

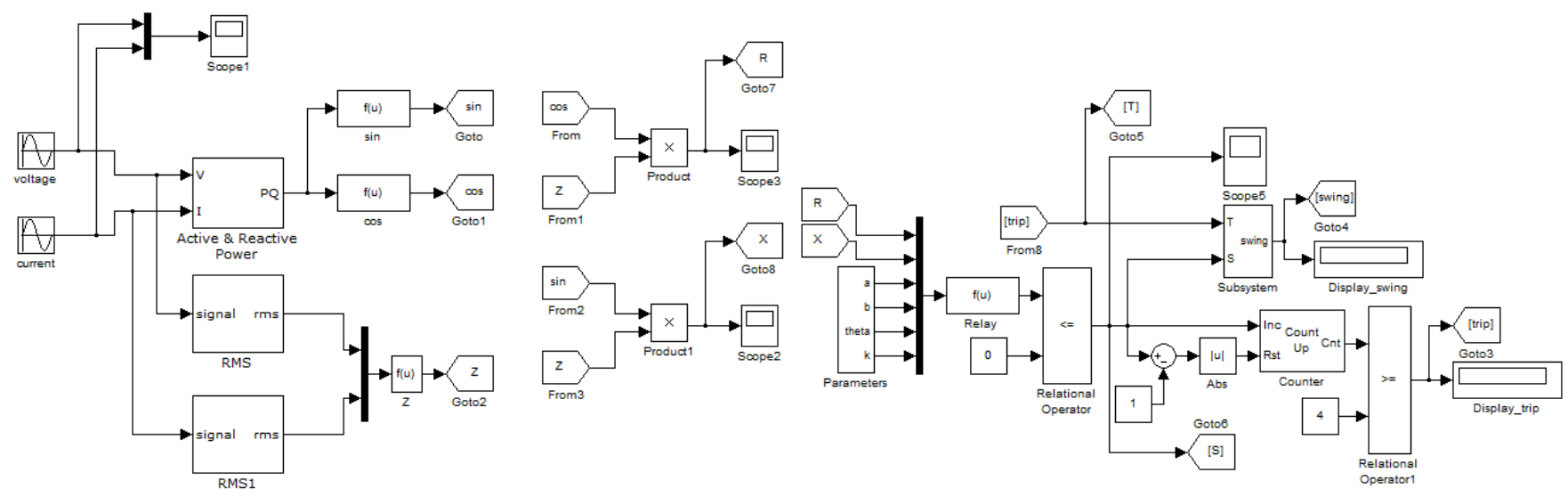

Figure 3: Simulation of elliptical relay using classical method

$$
\begin{aligned}
& \cos \phi=\frac{P}{\sqrt{P^{2}+Q^{2}}} \\
& \operatorname{Sin} \phi=\frac{Q}{\sqrt{P^{2}+Q^{2}}}
\end{aligned}
$$

For the calculation of resistance and reactance, impedance $\mathrm{Z}$

is calculated. The impedance is calculated as

$$
Z=\frac{V}{I}
$$

The resistance and reactance is thus given by

Where, $\mathrm{P}$ and $\mathrm{Q}$ are active and reactive power respectively.

$$
\begin{aligned}
& R=Z \cos \phi \\
& X=Z \sin \phi
\end{aligned}
$$

\subsection{Calculation of resistance and reactance}

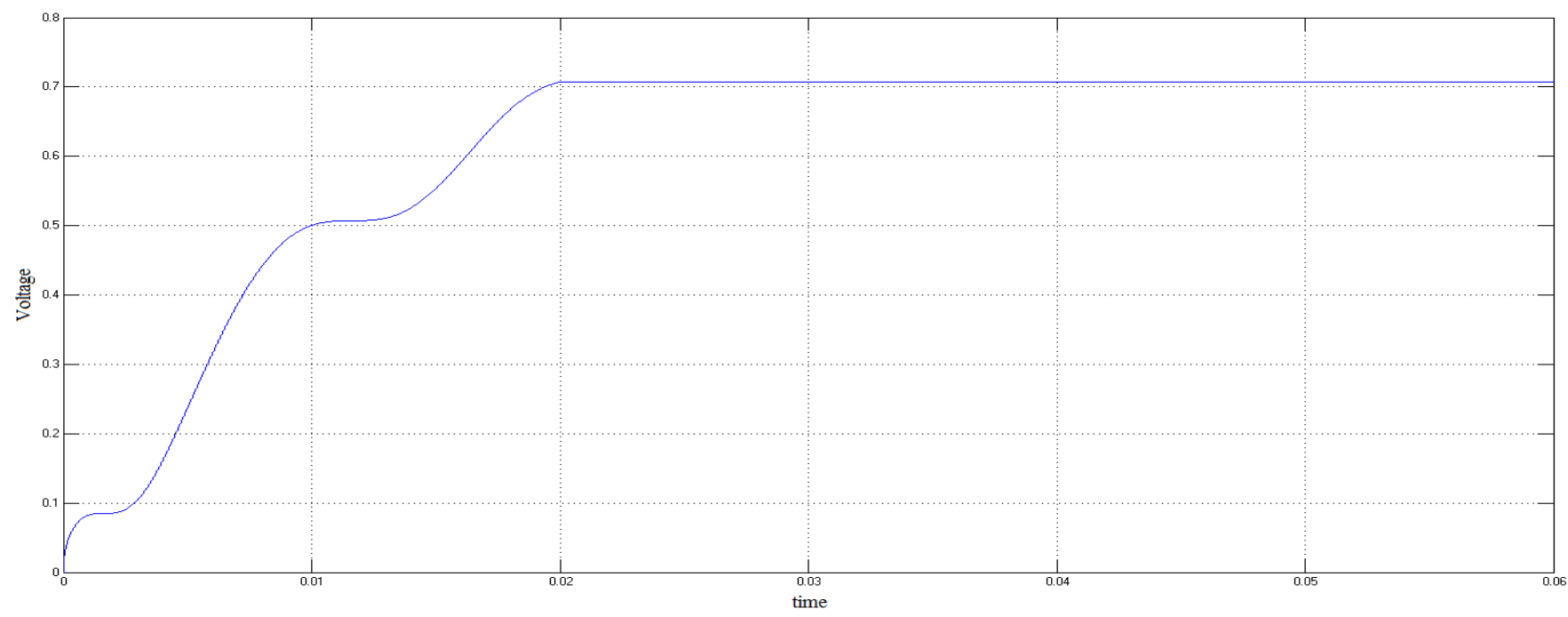

Figure 4: Plot for RMS value of voltage

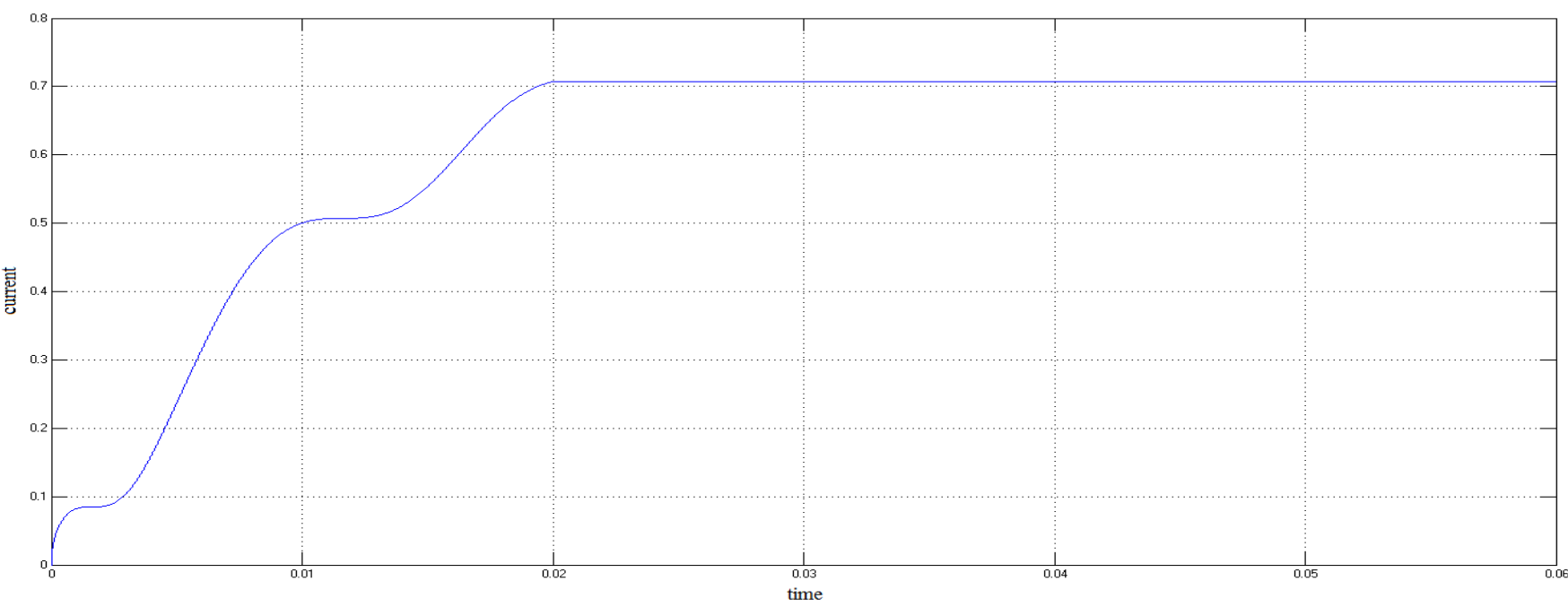

Figure 5: Plot for RMS value of current

Volume 5 Issue 5, May 2016 


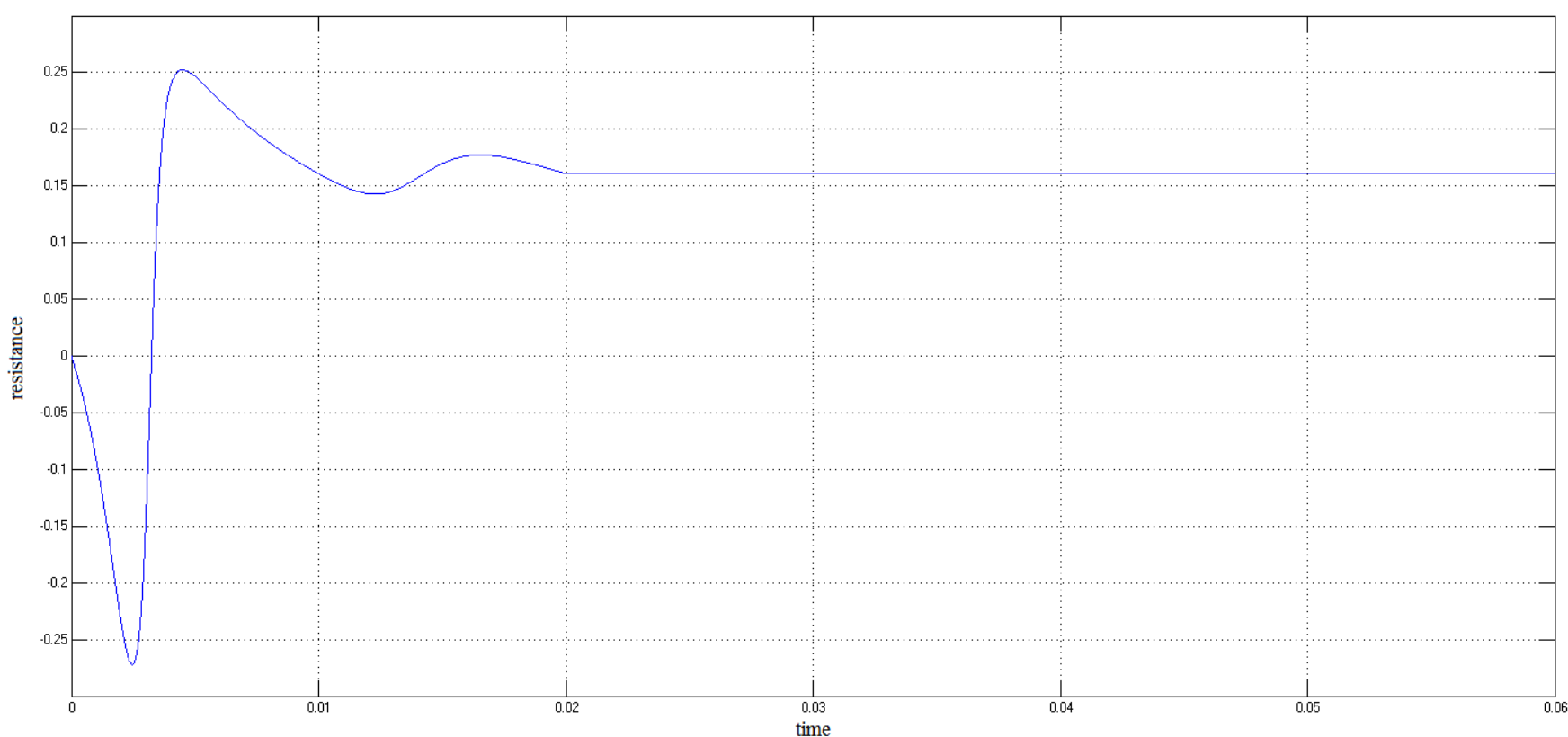

Figure 6: Plot for resistance calculated by classical method

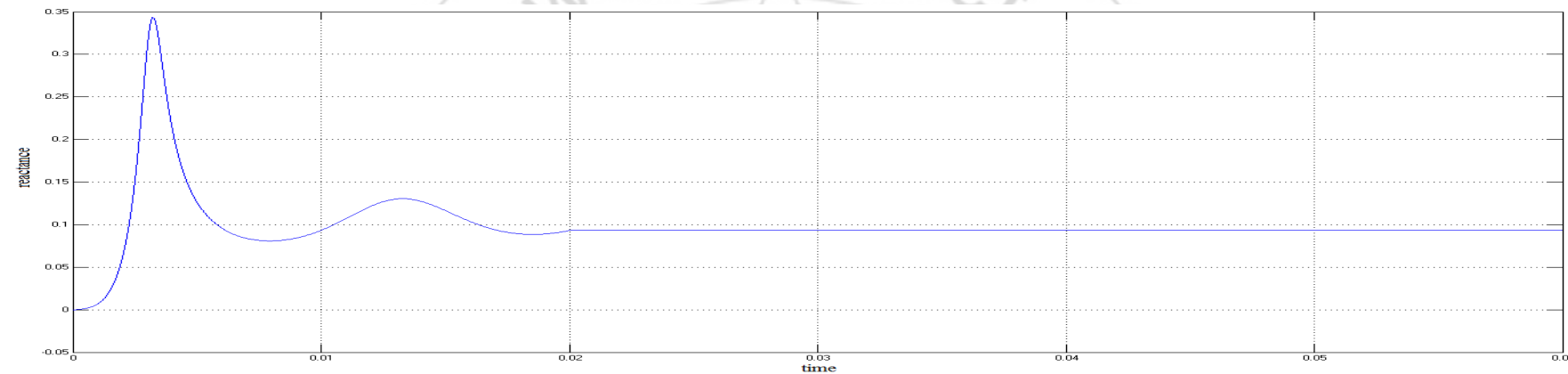

Figure 7: Plot for reactance calculated by classical method

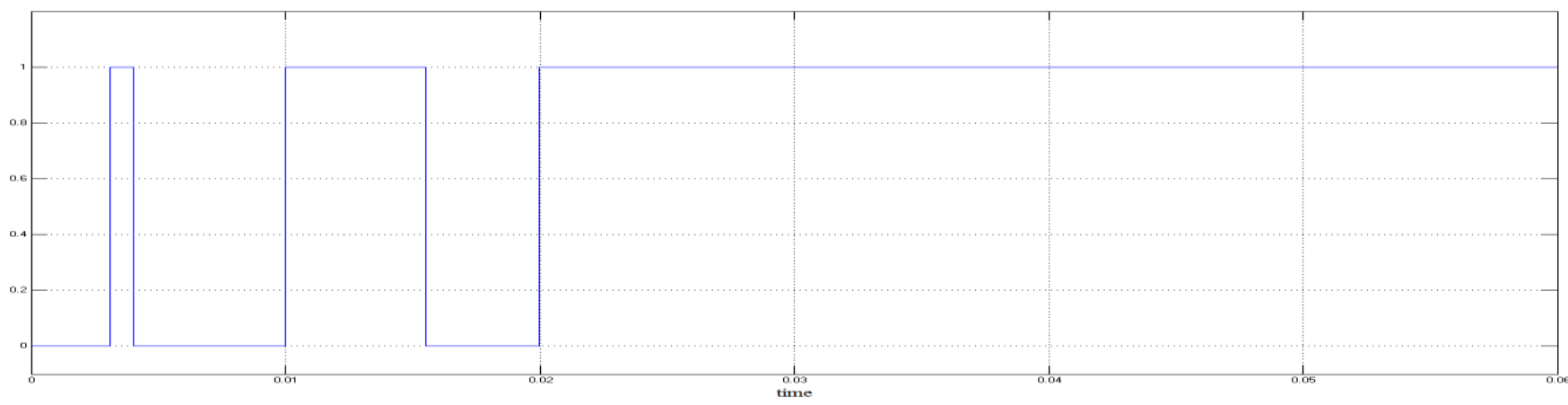

Figure 8: Trip signal using classical method

\subsection{Embedding elliptical relay characteristics}

As the values of resistance and reactance are calculated, the characteristics obtained from Equation 10 are incorporated. Also the parameters of line data are incorporated.

\subsection{Counter block}

Usually the tripping signal is not applied instantaneously. This is due to the transients that occur in the system. Hence a counter block is added. If the count is more than the preset value then the trip signal is initiated.

\section{Simulation results of elliptical relay in classical method using MATLAB software}

In order to check when the true RMS value of the signal is calculated, we simulated for voltage amplitude $=1 \mathrm{~V}$ and current amplitude $=1 \mathrm{~A}$. The current lags the voltage by 30 degrees. The results are shown in Figure 4 and Figure 5.

To check the trip condition, we considered the voltage amplitude to be $0.186 \mathrm{~V}$ and current amplitude to be $1 \mathrm{~A}$. The current lags voltage by 30 degrees. This condition is just inside the trip region of the relay $\mathrm{R}-\mathrm{X}$ characteristics. The calculated value of $\mathrm{R}$ and $\mathrm{X}$ is shown in Figure 6 and Figure 7 respectively. The trip signal is shown in Figure 8. 


\section{International Journal of Science and Research (IJSR) \\ ISSN (Online): 2319-7064}

Index Copernicus Value (2013): 6.14 $\mid$ Impact Factor (2015): 6.391

\section{Analysis and explanation of results for simulation in classical method}

From Figure 4 and Figure 5 we clearly see that the RMS values of voltage and current is calculated after one cycle. Figure 8 shows that the trip signal is generated reliably after one AC cycle. The trip signal before 0.02 seconds is because wrong values of RMS voltage and current (true RMS values are obtained after one AC cycle). As a result, the true value of resistance and reactance is calculated after one AC cycle. Hence in classical relay system, the trip signal and the decision making of relay is done after one AC cycle.
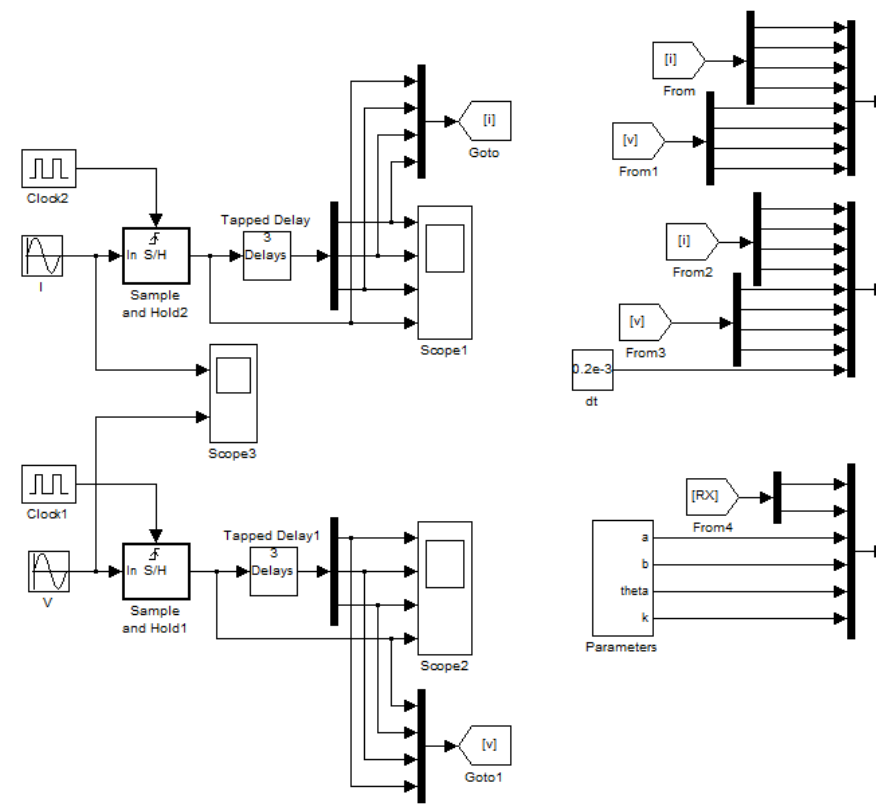

\section{Simulation of elliptical relay in proposed topology using MATLAB software}

To study the performance of elliptical relay, simulation was performed in MATLAB software using this technique. The test was carried out under various conditions and results were obtained. The supply frequency is $50 \mathrm{~Hz}$ and the sampling frequency is $5 \mathrm{KHz}$. That means there are 100 samples in one AC cycle. The simulation of relay in proposed method is shown in Figure 9.

Figure 9: Simulation of elliptical relay by proposed method

\subsection{Sampling}

Sampling is done using sample and hold circuit. The clock decides the frequency at which sampling is to be done. Using delays, four samples are obtained for the calculation of resistance and inductance.

\subsection{Calculation of resistance and inductance}

Using delay, the values of four samples is obtained. The four samples of voltage and current thus obtained are used to calculate the value of resistance and reactance. The sampling frequency is $5 \mathrm{KHz}$. Hence, $\Delta \mathrm{t}=0.2 \mathrm{~ms}$. Thus reactance can be obtained.

\subsection{Embedding elliptical relay characteristics}

Since resistance and reactance are calculated, the characteristics obtained from Equation. 10 are incorporated. The transmission line angle $\beta$ is given by
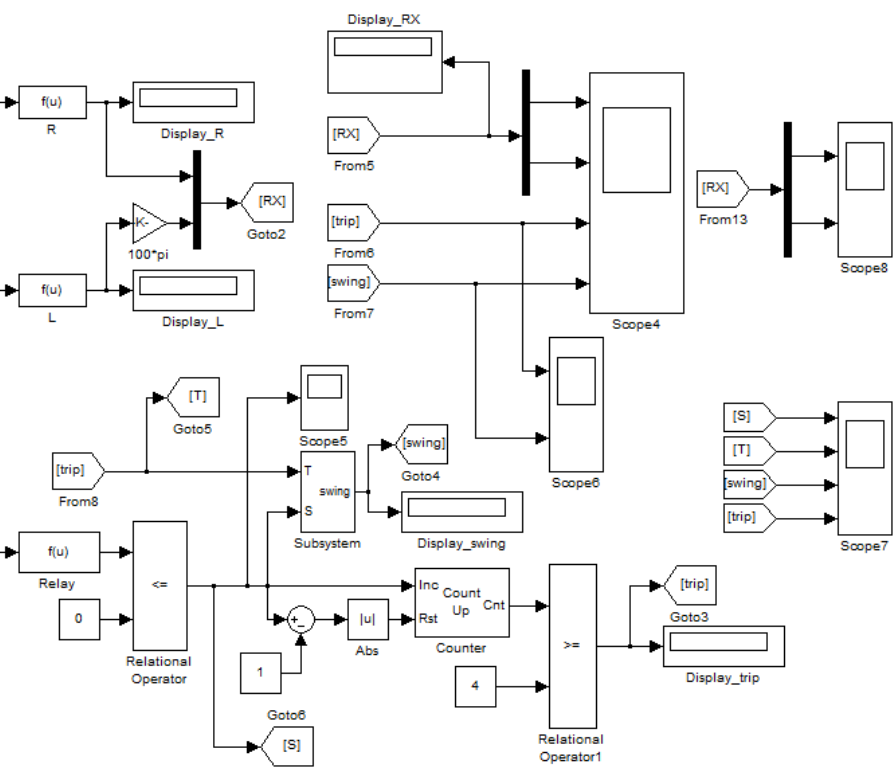

$$
\beta=\frac{\pi}{2}-\theta
$$

\subsection{Subsystem}

In order to distinguish between swing and trip signal, a subsystem is made. When swing is high and trip is low then system is said to be in transient state. By using K-map, we get the condition as $\mathrm{S}$ anded with negation of $\mathrm{T}$, where $\mathrm{S}$ is swing signal and $\mathrm{T}$ is trip signal. The subsystem is shown in Figure 10.

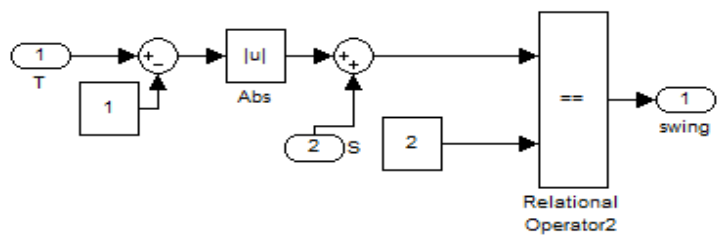

Figure 10: Subsystem 


\section{International Journal of Science and Research (IJSR) \\ ISSN (Online): 2319-7064}

Index Copernicus Value (2013): 6.14 | Impact Factor (2015): 6.391

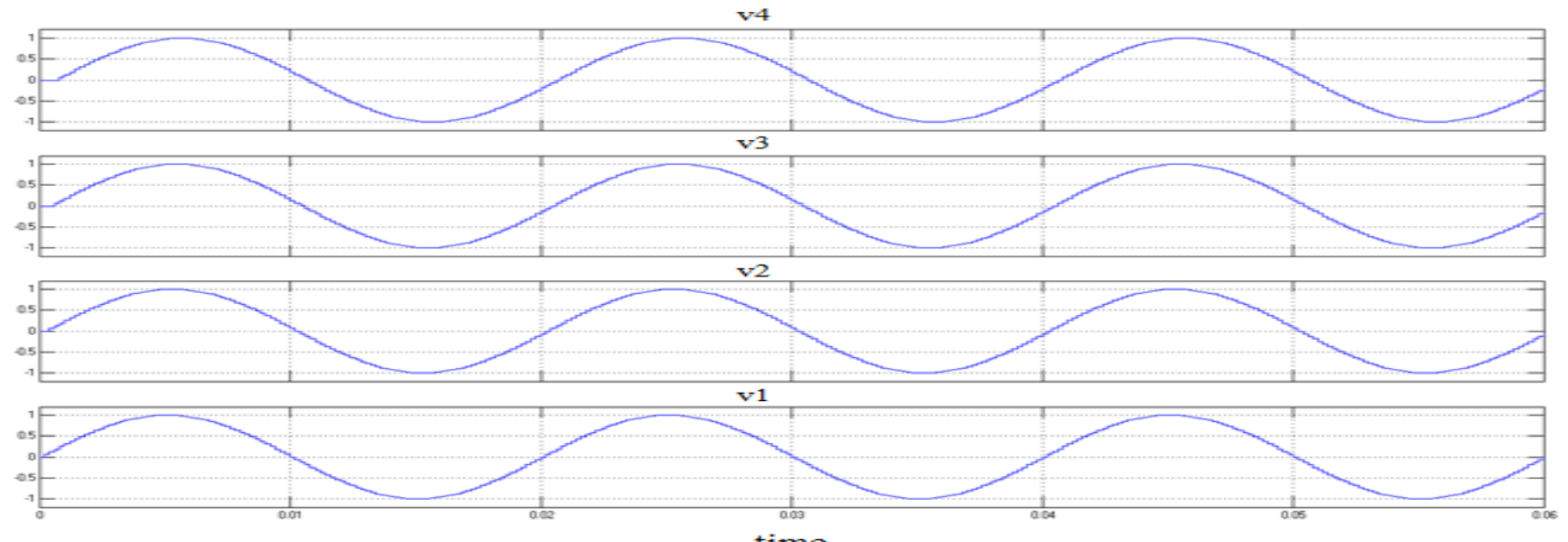

Figure 11: Sampled values of voltages (Voltage amplitude $=1 \mathrm{~V}$ )

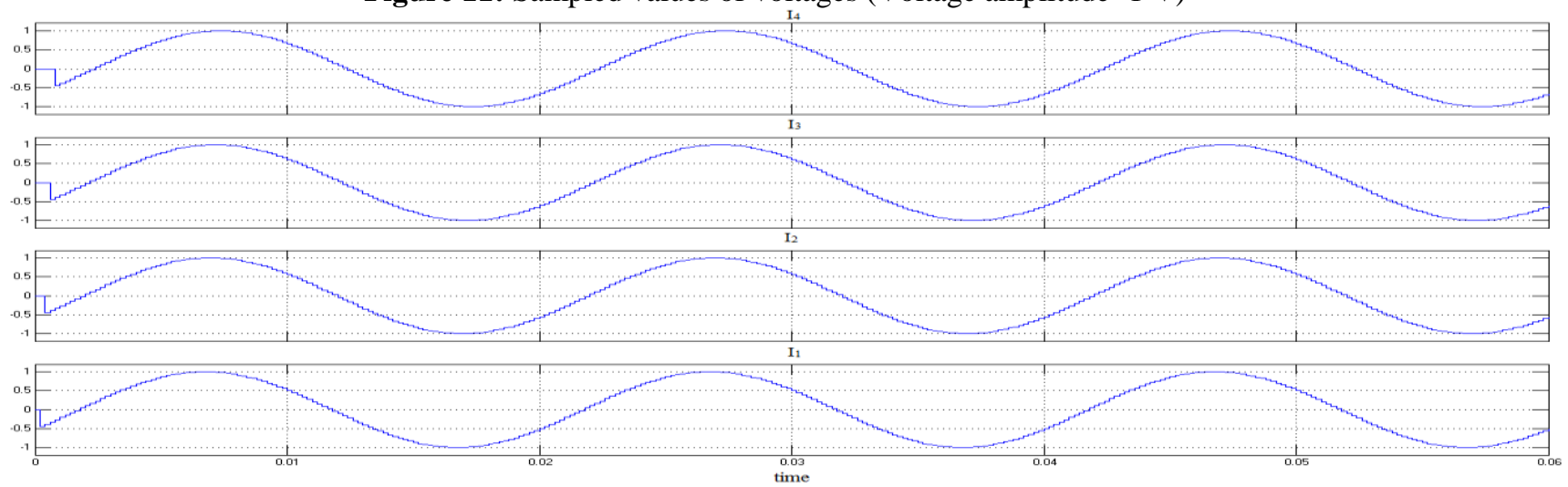

Figure 12: Sampled values of currents (Current amplitude=1 A) phase shifted by 30 degrees

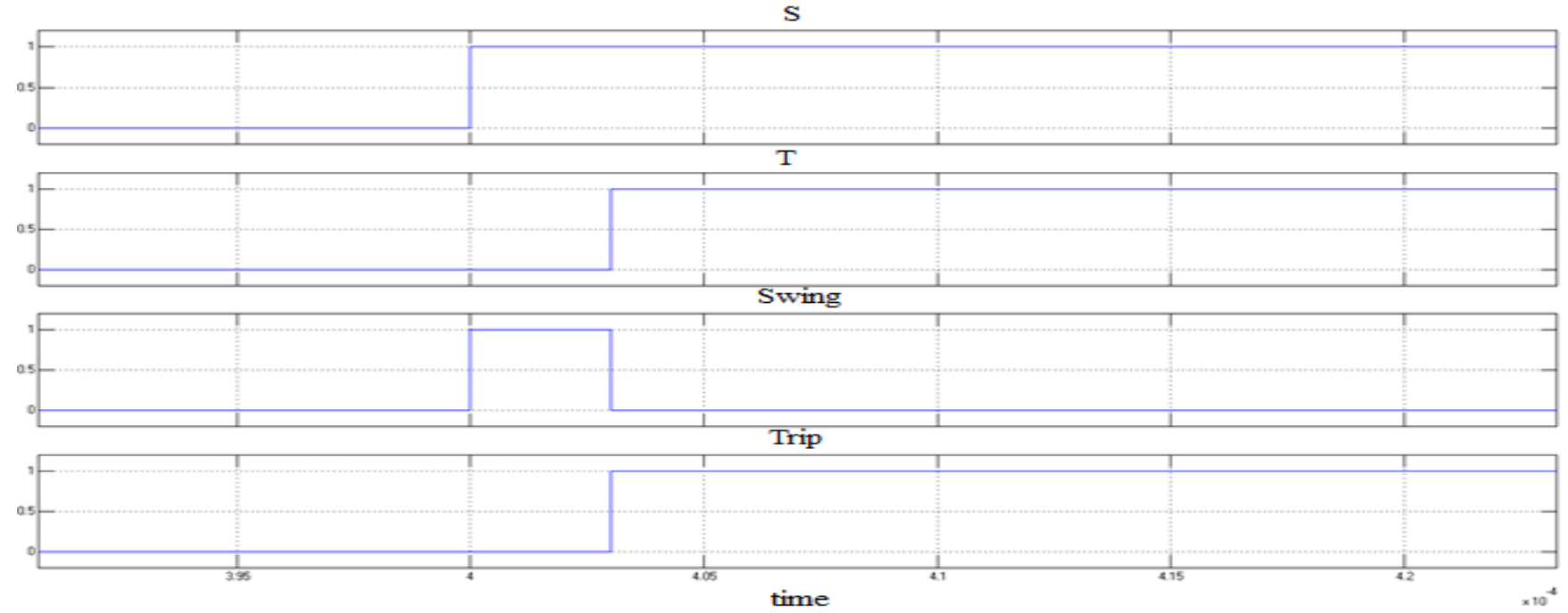

Figure 13: Signals of swing and trip

\subsection{Counter block}

To add delay for the tripping signal, counter block is added. The counter block resets if the transient disappears before the counter initializes the trip signal.

\section{Simulation results of elliptical relay for the proposed topology using MATLAB software}

The sampled waveform for voltage amplitude of $1 \mathrm{~V}$ and current amplitude of 1A along with delays is shown in Figure 11 and Figure 12 (Phase shift $=30$ degrees). $V_{1}, V_{2}, V_{3}, V_{4}$ are sampled values of voltage whereas $I_{1}, I_{2}, I_{3}, I_{4}$ are sampled values of current. Table 1 and 2 shows the trip signals obtained for currents of $1 \mathrm{~A}$ and $1.5 \mathrm{~A}$ respectively. The signal for swing and trip is shown in Figure 13.

\section{Volume 5 Issue 5, May 2016}




\section{International Journal of Science and Research (IJSR) \\ ISSN (Online): 2319-7064}

Index Copernicus Value (2013): 6.14 $\mid$ Impact Factor (2015): 6.391

Table 1: Simulation results for $\mathrm{I}=1 \mathrm{~A}$

\begin{tabular}{|c|c|c|c|c|}
\hline Phase (rad) & Current $(\mathrm{A})$ & Voltage $(\mathrm{V})$ & $\mathrm{R}$ & $\mathrm{X}$ \\
\hline 0 & 1 & 0.0414 & 0.0414 & 0 \\
\hline 0.157 & 1 & 0.0712 & 0.0703 & 0.0111 \\
\hline 0.314 & 1 & 0.1096 & 0.1042 & 0.0338 \\
\hline 0.471 & 1 & 0.1632 & 0.1454 & 0.0740 \\
\hline 0.628 & 1 & 0.2429 & 0.1966 & 0.1427 \\
\hline 0.785 & 1 & 0.3676 & 0.2600 & 0.2598 \\
\hline 0.942 & 1 & 0.5638 & 0.3316 & 0.4559 \\
\hline 1.099 & 1 & 0.8378 & 0.3807 & 0.7463 \\
\hline 1.256 & 1 & 1.0630 & 0.3291 & 1.0107 \\
\hline 1.413 & 1 & 0.9997 & 0.1571 & 0.9873 \\
\hline 1.57 & 1 & 0.7270 & 0.0005 & 0.7270 \\
\hline 1.9188 & 1 & 0.2854 & -0.0973 & 0.2683 \\
\hline 2.0933 & 1 & 0.1825 & -0.0911 & 0.1582 \\
\hline 2.2677 & 1 & 0.1175 & -0.0754 & 0.0901 \\
\hline 2.4422 & 1 & 0.0732 & -0.0560 & 0.0471 \\
\hline 2.6166 & 1 & 0.0401 & -0.0347 & 0.0201 \\
\hline 2.7911 & 1 & 0.0125 & -0.0117 & 0.0042 \\
\hline 2.9655 & 1 & -0.0135 & 0.0132 & -0.0023 \\
\hline
\end{tabular}

Table 2: Simulation results for $\mathrm{I}=1.5 \mathrm{~A}$

\begin{tabular}{|c|c|c|c|c|}
\hline Phase $(\mathrm{rad})$ & Current $(\mathrm{A})$ & Voltage $(\mathrm{V})$ & $\mathrm{R}$ & $\mathrm{X}$ \\
\hline 0 & 1.5 & 0.0621 & 0.0414 & 0 \\
\hline 0.157 & 1.5 & 0.1068 & 0.0703 & 0.0111 \\
\hline 0.314 & 1.5 & 0.1644 & 0.1042 & 0.0338 \\
\hline 0.471 & 1.5 & 0.2448 & 0.1454 & 0.0740 \\
\hline 0.628 & 1.5 & 0.3644 & 0.1966 & 0.1427 \\
\hline 0.785 & 1.5 & 0.5514 & 0.2600 & 0.2598 \\
\hline 0.942 & 1.5 & 0.8457 & 0.3316 & 0.4559 \\
\hline 1.099 & 1.5 & 1.2568 & 0.3807 & 0.7463 \\
\hline 1.256 & 1.5 & 1.5945 & 0.3291 & 1.0107 \\
\hline 1.413 & 1.5 & 1.4996 & 0.1571 & 0.9873 \\
\hline 1.57 & 1.5 & 1.0905 & 0.0005 & 0.7270 \\
\hline 1.9188 & 1.5 & 0.4282 & -0.0973 & 0.2683 \\
\hline 2.0933 & 1.5 & 0.2738 & -0.0911 & 0.1582 \\
\hline 2.2677 & 1.5 & 0.1763 & -0.0754 & 0.0901 \\
\hline 2.4422 & 1.5 & 0.1099 & -0.0560 & 0.0471 \\
\hline 2.6166 & 1.5 & 0.0601 & -0.0347 & 0.0201 \\
\hline 2.7911 & 1.5 & 0.0187 & -0.0117 & 0.0042 \\
\hline 2.9655 & 1.5 & -0.0201 & 0.0132 & -0.0023 \\
\hline
\end{tabular}

\section{Analysis and explanation of results for simulation of elliptical relay using proposed topology}

Since the resistance and reactance is calculated by using four samples, the trip signal is generated before one AC cycle. This can be verified in Figure 13 in which trip signal is generated in $0.403 \mathrm{~ms}$. The counter count can be increased to increase the delay of tripping signal. The elliptical relay characteristics is obtained and verified as shown in Figure 14

\section{Advantages of this method}

1) Since this technique uses four samples for the calculation of Rand X, the relay operation is very fast.

2) Compatible to the microcontroller.

3) Since it can be used in microcontroller, the VA burden of CTs and PTs are reduced. Thus the number of components required is reduced.

4) Flexibility is increased.

5) Since this technique is compatible to microcontroller, operational logic can be used to control the operation of transmission lines.

\section{Conclusion}

Elliptical relay is least affected by power swing. The proposed algorithm is much faster than the classical method. It takes only four samples for its operation. Hence it is very fast to operate as compared to other elliptical relay. Thus elliptical relay if used by this technique will generate trip signal in very short time which is useful for protection of long transmission lines.

\section{References}

[1] Y.G Paithankar and S.R Bhide, Fundamentals of power system protection, Prentice Hall of India Private Limited, 2003.

[2] Badri Ram and D.N. Vishwakarma, Power System Protection and Switchgear, McGraw Hill Education (India) Private Limited, 2013.

[3] P. Kundur, Power System Stability and Control, McGraw Hill Education (India) Private Limited, 2013.

[4] Ramakant A. Gayakawad, Phi Learning private Limited, 2012.

\section{Author Profile}

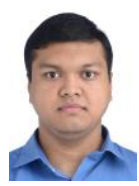

Abhishek Bagh received the Bachelor degree in Electrical Engineering from Shri Ramceobaba College of Engineering and Management in 2014. He is currently pursuing $M$. Tech in Shri Ramdeobaba College of Engineering and Management

T.G Arora was born in Nagpur, India, on June 20,

Figure 14: $\mathrm{R}-\mathrm{X}$ diagram obtained using for $\mathrm{I}=1.5$ A using MATLAB software 1961. He received the B.E. degree in Electrical Engineering from the Government College of

Engineering, Amravati, Maharashtra, India, in 1983

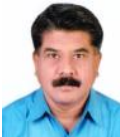




\section{International Journal of Science and Research (IJSR) \\ ISSN (Online): 2319-7064}

Index Copernicus Value (2013): 6.14 | Impact Factor (2015): 6.391

and M.Tech. degree from Visvesvaraya Regional College of Engineering, Nagpur, Maharashtra, India, in 1985. He has submitted the Ph.D. thesis in the area of High Voltage Engineering in Rastrasant Tukadoji Maharaj Nagpur University, Nagpur, Maharashtra, India. From 1985 to 1986, he was a Research Assistant with the Visvesvaraya Regional College of Engineering, Nagpur. Since 1986, he is an Associate Professor in Electrical Engineering Department of Shri Ramdeobaba College of Engineering and Management, Nagpur, India. He has published 10 articles. His research interests include insulation breakdown and discharges under non-sinusoidal waveforms and power system protection. T. G. Arora is the fellow of Institution of Engineers (India) and life member of Indian Society for Technical Education.

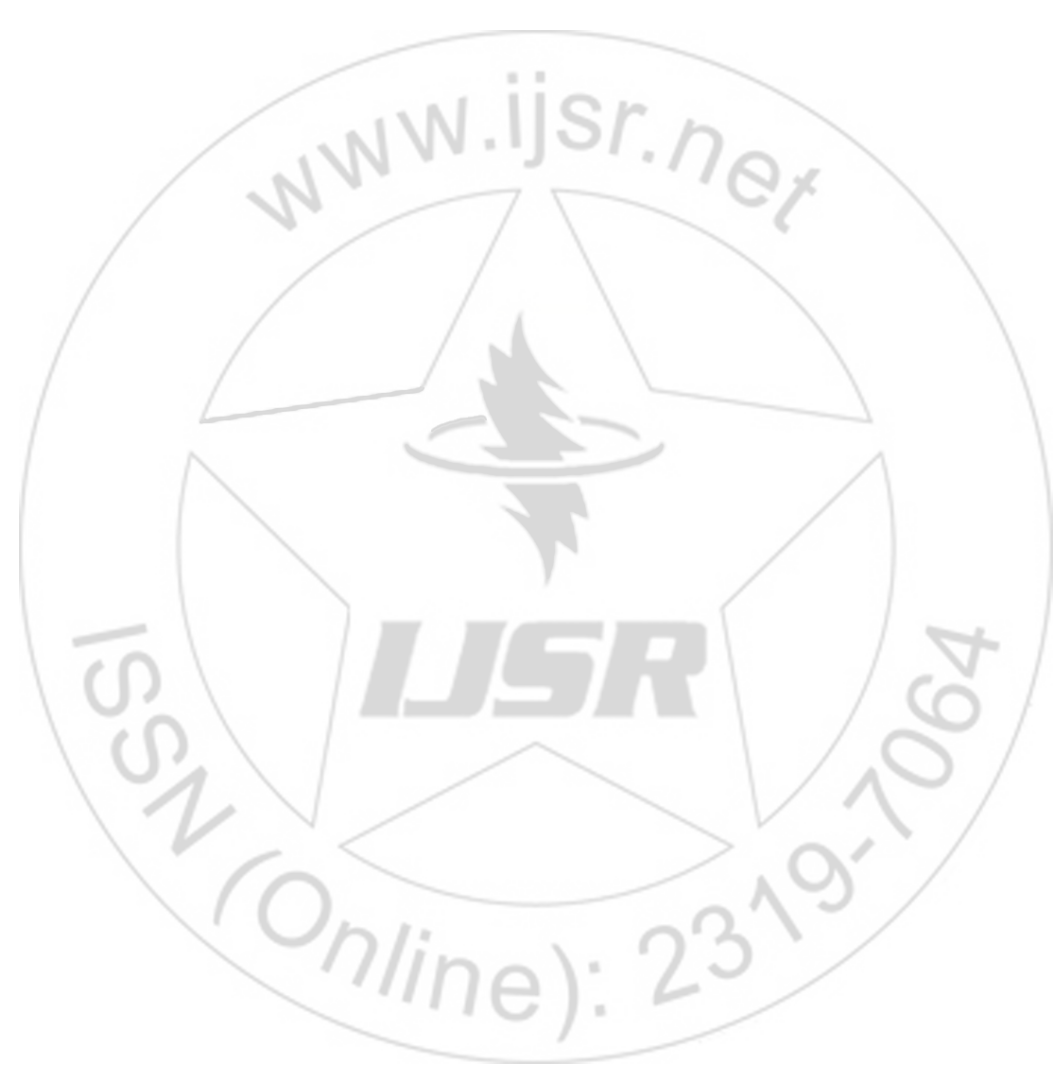

